Article

\title{
Burnout Syndrome, Engagement and Goal Orientation in Teachers from Different Educational Stages
}

\author{
Pablo Usán Supervía ${ }^{1,2}$ (D) and Carlos Salavera Bordás $1,2, *$ (D) \\ 1 Departament of Psychology, Faculty of Education, University of Zaragoza, 50009 Zaragoza, Spain; \\ pusan@unizar.es \\ 2 OPIICS Research Group, University of Zaragoza, 50009 Zaragoza, Spain \\ * Correspondence: salavera@unizar.es
}

Received: 16 June 2020; Accepted: 11 August 2020; Published: 24 August 2020

check for updates

\begin{abstract}
Teaching is a demanding occupation, physically, mentally, and emotionally, that, depending on personal characteristics, can have a negative impact on health and personal wellbeing, which can affect the way professors work and teach in schools. The aim of this study is to analyze the relationship between burnout, engagement, and goal orientation in a sample of teachers from different educational stages. The sample comprised 576 teachers from different schools, both male $(\mathrm{N}=244 ; 42.36 \%)$ and female $(\mathrm{N}=332 ; 57.63 \%)$ aged between 21 and 65 years $(\mathrm{M}=38.55 ; \mathrm{DT}=12.15)$. The instruments used were the Maslach Burnout Inventory-General Survey (MBI-GS), the Work Engagement Scale (UWES) and the Perception of Success Questionnaire (POSQ). The results revealed that task orientation presents a significant correlation with engagement and self-efficacy, and negative correlation with burnout, in line with adaptive behaviors, and that ego orientation is correlated with engagement and commitment. It is concluded that both forms of goal orientation have a positive effect on teacher commitment and that they help to prevent burnout syndrome and also that self-efficacy plays a role in determining goal orientation in teachers in their work assignments.
\end{abstract}

Keywords: Burnout; engagement; goal orientation; teachers; education

\section{Introduction:}

In its broadest sense, education is a key factor in social development, and one which confronts many challenges. Teachers are the cornerstone of education, playing a central role in learning/teaching processes. Essential variables in this regard are training and professional performance, learning strategies, resources and ability to motivate students [1]. Contextual conditions, as well as individual commitment and personal characteristics, can lead to more or less prolonged episodes of stress and exhaustion [2].

Teachers are regarded as especially vulnerable to physical problems such as headaches and mental health issues such as anxiety, stress, and depression, as well to behavioral problems leading to medical leaves, lack of commitment, and even absenteeism [3].

Therefore, the variables studied of our research are burnout, engagement, and goal orientations of teachers whose relationships will help us to understand the psychological processes of teachers as well as their emotional wellbeing, keys to their optimal professional performance that will affect in their way of working and teaching their students in the schools.

Firstly, burnout syndrome is defined as a persistent and negative emotional state [4] characterized by a general feeling of psychological unrest and low levels of professional self-esteem, motivation, and commitment. Burnout syndrome is the outcome of long-term stress caused by the subject's professional environment [5]. 
Burnout is divided into three main dimensions: Emotional exhaustion, cynicism, and self-efficacy. The first dimension refers to a feeling of professional emptiness and lack of energy to cope with professional challenges. The second dimension alludes to an insensitive or apathetic response to professional duties, and the third refers to the professional's perception of his or her own ability to deal with their professional challenges, potentially leading to feelings of failure, incompetence, and low self-esteem.

Studies about burnout syndrome in teachers establish a relationship with factors related to emotional exhaustion caused by overworking [6] little professional autonomy [7], excessive deadlines [8], interpersonal conflicts with other members of the school community [9], and poor organizational health [2].

On the other hand, it has been pointed out that personal cognitive factors have a significant effect on the ability of individuals to cope with these problems [10].

Engagement is defined as a positive psychological state that boosts motivation and the individual's ability to cope with situations of stress and exhaustion [11]. It is divided into three main motivations: Vigor, dedication, and absorption.

Following Armijo and Portalanza [12] vigor is defined as the strength and motivation that energize the individual in his or her professional duties. Dedication refers to the ability to work hard, follow the guidelines and develop the initiative to confront professional challenges. Absorption refers to the individual's ability to become immersed in his or her work in a satisfactory and committed way.

Individuals with high levels of engagement also present high levels of concentration and commitment. Time spent in dealing with professional duties goes fast, and their professional performance is proactive and energetic [13].

In the field of education, professionals may undergo periods of burnout owing to changes in their professional conditions, leading to changes in motivation and undermining engagement [12]. Vicente and Gabari [2] point out that highly engaged professionals connect with their professional duties, showing high levels of interest, vitality, engagement, and dedication.

Existing studies agree that engagement and burnout in education are negatively correlated, that is, teachers who present high levels of engagement tend to present low levels of burnout $[14,15]$.

One of the most relevant cognitive-social theories in the study of school motivation is the achievement goal theory [16,17]. This refers to the goals or reasons that guide teachers in their professional behavior in achievement environments. Goal orientation defines the psychological process that outlines personal goals, as well as the motivations that guide individual actions towards reaching that goal [18].

Two goal orientations have been defined: Task orientation is related to more intrinsic and adaptive behaviors, and is characterized by a desire to focus on the task at hand for itself, ego orientation, which is related to less adaptive and more extrinsic behaviors, is characterized by a focus on performance and external gratification and recognition [19].

Therefore, the goal orientation theory analyses different motivational responses to professional duties [17].

Studies about goal orientation in teachers are few, despite the fact that this can directly affect their professional performance, their students, and personal and contextual variables, which are directly related to burnout syndrome and engagement.

Goal orientation in teachers has been related to improved teaching strategies [17] higher levels of personal self-efficacy [18], and better professional performance [2]. Ego orientation has been linked to poor adaptive skills and low levels of personal and professional wellbeing [20].

Therefore, it is argued that these three constructs play a key role in the professional and personal wellbeing of teachers, also having a direct effect on professional performance and their ability to have a positive impact on their students [19].

In order to contribute to overcoming the lack of studies that analyze the direct relationship between the three constructs, this study aims to examine the relationship between burnout syndrome, 
engagement, and goal orientation in teachers from different educational stages. This objective will help us to understand different research questions about teachers' psychological processes and their emotional wellbeing as a cornerstone in teaching-learning proceedings.

Four hypotheses are set forth:

Hypothesis 1: Goal orientation is positively correlated with engagement and self-efficacy in line with more adaptive conducts.

Hypothesis 2: Ego orientation is positively correlated with emotional exhaustion and cynicism in line with less adaptive conducts.

Hypothesis 3: Engagement and self-efficacy variables can be used to predict goal orientation.

Hypothesis 4: Burnout and engagement variables can be used to predict ego orientation.

\section{Method}

\subsection{Sample}

The sample comprised 576 teachers from different schools, both male $(\mathrm{N}=244 ; 42.36 \%)$ and female $(\mathrm{N}=332 ; 57.63 \%)$ aged between 21 and 65 years $(\mathrm{M}=38.55 ; \mathrm{DT}=12.15)$. The questionnaires were sent to all the schools in the city, to be filled by all the teachers who wished to do so. The questionnaires were collected between April and June 2019.

\subsection{Instruments}

Three questionnaires were used to measure the variables under consideration.

Burnout syndrome was measured with the Maslach Burnout Inventory-General Survey (MBI-GS) proposed by Schaufeli et al. [21], which was previously translated into Spanish and validated by Bresó et al. [22]. This questionnaire comprises 15 items distributed in three dimensions: Physical/emotional exhaustion (5) ( $\alpha=0.79)$ (e.g., "I feel emotionally exhausted at work"), cynicism (4) $(\alpha=0.81)$ (e.g., "I just want to do my job without being bothered"), and self-efficacy (6) $(\alpha=0.80)$ (e.g., "I can cope with work-related problems"). Responses are structured on a Likert-type scale and range from "Completely disagree" (1) to "Completely agree" (5). The original questionnaire yields a Cronbach's alpha value of 0.81 , while in this study it yielded a value of 0.80 .

Engagement was measured with the Work Engagement Scale (UWES) [23]. This instrument comprises 17 items distributed in three dimensions: Vigor (6) $(\alpha=0.79)$ (e.g., "At my work I feel bursting with energy"), dedication (5) ( $\alpha=0.83$ ) (e.g., "I am proud of the work that I do"), and absorption (6) $(\alpha=0.78)$ (e.g., "Time flies when I am at work"). Responses are structured on a Likert-type scale and range from "Completely disagree" (1) to "Completely agree" (5). The original questionnaire yields a Cronbach's alpha value of 0.81 , while in this study, it yielded a value of 0.82 .

Achievement goals were measured through the use of Roberts et al.'s Perception of Success Questionnaire (POSQ) [24], which was previously translated into Spanish and validated by Martínez et al. [25]. This questionnaire includes 12 items to measure achievement goals with two dimensions: Task-oriented (6) (e.g., "When I'm at work, I perform to the best of my ability") and ego-oriented (6) (e.g., "When I'm at work, I feel successful when I show my peers that I am the best"). Answers express the teachers' degree of agreement or disagreement on a Likert-type scale that ranges from "Strongly disagree" (1) to "Strongly agree" (5). The reliability of this questionnaire has been confirmed by several studies conducted in school contexts. It yields Cronbach's alpha values of 0.86 for the task subscale and 0.90 for the ego subscale and values of 0.83 and 0.86 , respectively, in our study. 


\subsection{Protocol}

Schools were contacted and informed about the purpose of the study and participants had to sign an informed consent form. All teachers were informed about the nature of the study, in accordance with all the ethical guidelines set out in the Declaration of Helsinki [26]. The study protocol was approved by the Ethics Review Committee of the Psychology and Sociology Department-University of Zaragoza. All questionnaires were anonymous, and participation was voluntary. All participants were allowed to drop out of the study at any point if they so wished.

\subsection{Data analysis}

Descriptive statistics were used to assess the sample's socio-demographic background as well as the data and the other variables under consideration. Subsequently, correlations between goal orientation, burnout, and engagement were examined with the aid of the SPSS v26.0 (IBM, Armonk, NY, USA). Stepwise multiple regression was carried out to estimate the predictive value of goal orientation and engagement over burnout. This analysis allows the generation of a linear model in which the value of the dependent variable (goal orientation-task and goal orientation-ego) is determined from a set of independent variables called predictors (burnout syndrome and engagement). Finally, a structural equations model was applied using the maximum likelihood method to validate and quantify the causal relations between the three variables (burnout, engagement, and goal orientation) with AMOS v24 software (IBM) in order to approach the objective and hypothesis of our study. All the calculations adopted a $p \leq 0.05$ level of significance and a $95 \%$ confidence level.

\section{Results}

\subsection{Demographic Variables:}

The sample comprised 576 teachers from different schools, both male $(\mathrm{N}=244 ; 42.36 \%)$ and female $(\mathrm{N}=332 ; 57.63 \%)$ aged between 21 and 65 years $(\mathrm{M}=38.55$; DT $=12.15)($ Table 1$)$.

Table 1. Socio-demographic data of the sample.

\begin{tabular}{cccc}
\hline \multirow{2}{*}{ Gender } & & $\mathbf{N}$ & \% \\
\hline \multirow{2}{*}{ Age } & Male & 244 & 42.36 \\
& Female & 332 & 57.63 \\
\hline \multirow{3}{*}{ Educational stage } & From 21 to 35 years & 119 & 20.65 \\
& From 36 to 45 years & 186 & 32.29 \\
& From 46 to 55 years & 207 & 35.93 \\
& From 56 to 65 years & 43 & 11.1 \\
\hline \multirow{2}{*}{ Type of school } & Kindergarten & 163 & 28.29 \\
& Primary school & 172 & 29.86 \\
& Secondary school & 198 & 34.37 \\
& University & 43 & 7.46 \\
\hline \multirow{2}{*}{ Teaching experience } & Public & 379 & 65.79 \\
& Private & 197 & 34.20 \\
\hline & Below 5 years & 34 & 5.90 \\
& 5 to10 years & 101 & 17.53 \\
& 10 to 15 years & 131 & 22.74 \\
& 15 to 20 years & 104 & 18.05 \\
& Over 20 years & 206 & 35.76 \\
\hline
\end{tabular}




\subsection{Descriptive Variables}

As illustrated in Table 2, no major differences were attested in responses according to gender. Burnout and engagement values tend to be slightly higher in males and goal orientation values in females. Based on Cohen's $d$, self-efficacy is, on average, slightly higher in males (0.243).

Table 2. Results of burnout, engagement, and goal orientation descriptive variables.

\begin{tabular}{cccccccc}
\hline & \multicolumn{2}{c}{ Total } & \multicolumn{2}{c}{ Males } & \multicolumn{2}{c}{ Females } \\
\hline & $x$ & $s d$ & $x$ & $s d$ & $x$ & $s d$ & Cohen's $d$ \\
\hline Emotional exhaustion & 3.04 & 1.07 & 3.12 & 0.93 & 2.98 & 1.17 & 0.132 \\
Cynicism & 1.94 & 0.99 & 1.97 & 0.95 & 1.92 & 1.01 & 0.050 \\
Personal efficacy & 3.54 & 0.88 & 3.66 & 0.79 & 3.45 & 0.93 & 0.243 \\
\hline Vigor & 2.79 & 1.01 & 2.83 & 1.05 & 2.77 & 0.99 & 0.058 \\
Dedication & 3.24 & 0.96 & 3.31 & 1.02 & 3.18 & 0.92 & 0.133 \\
Absorption & 2.91 & 0.80 & 2.96 & 0.86 & 2.87 & 0.75 & 0.111 \\
\hline Goal orientation (Task) & 3.94 & 0.77 & 3.88 & 0.85 & 3.99 & 0.70 & -0.141 \\
Goal orientation (Ego) & 3.04 & 1.01 & 2.98 & 0.99 & 3.08 & 1.04 & -0.098 \\
\hline
\end{tabular}

\subsection{Correlation Analysis Between Burnout, Engagement, and Goal Orientation}

The analysis of the variables revealed significant correlations between goal orientation, burnout, and engagement (see Table 3).

Table 3. Correlation analysis between goal orientation, burnout, and engagement.

\begin{tabular}{|c|c|c|c|c|c|c|c|c|}
\hline & 1 & 2 & 3 & 4 & 5 & 6 & 7 & 8 \\
\hline 1. Emotional exhaustion & 1 & & & & & & & \\
\hline 2. Cynicism & $0.390 * *$ & 1 & & & & & & \\
\hline 3. Self-efficacy & 0.046 & $-0.308^{* *}$ & 1 & & & & & \\
\hline 4. Vigor & $-0.120 *$ & $-0.198^{* *}$ & $0.556^{* *}$ & 1 & & & & \\
\hline 5. Dedication & -0.052 & $-0.369 * *$ & $0.668 * *$ & $0.696^{* *}$ & 1 & & & \\
\hline 6. Absorption & -0.069 & $-0.321^{* *}$ & $0.549 * *$ & $0.629 * *$ & $0.643^{* *}$ & 1 & & \\
\hline 7. Goal orientation (Task) & -0.045 & $-0.362 * *$ & $0.527^{* *}$ & $0.387^{* *}$ & $0.490 * *$ & $0.354 * *$ & 1 & \\
\hline 8. Goal orientation (Ego) & 0.071 & -0.068 & $0.236^{* *}$ & $0.149 *$ & $0.158^{* *}$ & $0.173^{* *}$ & $0.283^{* *}$ & 1 \\
\hline Average & 3.04 & 1.94 & 3.54 & 2.79 & 3.24 & 2.91 & 3.94 & 3.04 \\
\hline DT & 1.07 & 0.99 & 0.88 & 1.01 & 0.96 & 0.80 & 0.77 & 1.01 \\
\hline Cronbach's alpha & 0.79 & 0.81 & 0.79 & 0.83 & 0.78 & 0.77 & 0.83 & 0.86 \\
\hline
\end{tabular}

Note: ${ }^{* *}$ The correlation is significant at 0.01 (bilateral); ${ }^{*}$ The correlation is significant at 0.05 (bilateral).

Concerning burnout-related dimensions, cynicism presented a significant negative correlation with all engagement-related dimensions, vigor $(r=-0.198)$, dedication $(r=-0.369)$, and absorption $(r=-0.321)$, and with task orientation $(r=-0.362)$. Self-efficacy was shown to be positively correlated with task orientation $(r=0.527)$ and ego orientation $(r=0.236)$. Finally, emotional exhaustion is negatively correlated with vigor $(r=-0.120)$.

On the other hand, the different dimensions of academic engagement are positively correlated with task orientation and, to a lesser extent, with ego orientation.

\subsection{Regression Analysis of Burnout and Engagement as Predictors of Goal Orientation}

Two regression analyses were conducted using burnout and engagement as predictor variables and goal orientation (Task and Ego) as criterion variable. Tables 4 and 5 show the steps in the models with the introduction of the explicative variables that have a significant effect on the likelihood of predicting goal orientation. 
Table 4. Burnout and engagement as predictor variables for goal orientation (task).

\begin{tabular}{ccccccc}
\hline & & $\boldsymbol{B}$ & s.e. & $\boldsymbol{R}^{\mathbf{2}}$ & $\boldsymbol{t}$ & Sig. \\
\hline \multirow{2}{*}{ Step 1 } & (Constant) & 2.308 & 0.161 & 0.275 & 14.334 & 0.000 \\
& Self-efficacy & 0.463 & 0.044 & & 10.483 & 0.000 \\
\hline \multirow{2}{*}{ Step 2 } & (Constant) & 2.854 & 0.201 & 0.317 & 14.164 & 0.000 \\
& Self-efficacy & 0.403 & 0.045 & & 8.951 & 0.000 \\
& Cynicism & -0.172 & 0.040 & & -4.293 & 0.000 \\
\hline \multirow{2}{*}{ Step 3 } & (Constant) & 2666 & 0.209 & 0.335 & 12.765 & 0.000 \\
& Self-efficacy & 0.298 & 0.057 & & 5.226 & 0.000 \\
& Cynicism & -0.144 & 0.041 & & -3.556 & 0.000 \\
& Dedication & 0.156 & 0.053 & & 2.943 & 0.004 \\
\hline
\end{tabular}

Note: Excluded variables: Emotional exhaustion (burnout), vigor and absorption (engagement).

Table 5. Burnout and engagement as predictors of goal orientation (Ego).

\begin{tabular}{ccccccc}
\hline & & $\boldsymbol{B}$ & s.e. & $\boldsymbol{R}^{2}$ & $\boldsymbol{t}$ & Sig. \\
\hline \multirow{2}{*}{ Step 1 } & (Constant) & 2.076 & 0.242 & 0.236 & 8.565 & 0.000 \\
& Self-efficacy & 0.273 & 0.066 & & 4.115 & 0.000 \\
\hline
\end{tabular}

Note: Excluded variables: Emotional exhaustion and cynicism (burnout), vigor, dedication and absorption (engagement).

The first model (Table 4) suggests that self-efficacy and dedication (positive correlation) and burnout (negative correlation) can be used to predict goal orientation (task). Nagelkerke's $R^{2^{\prime}}$ yielded an adjustment level of 0.335 for goal orientation (task).

Concerning goal orientation (ego) (Table 5) the predictive values were less pronounced. Nagelkerke's $R$ yielded a result of 0.236 for self-efficacy, which was the only variable found to have predictive value.

\subsection{Structural Equations Model for Goal Orientation, Burnout, and Academic Performance}

Finally, calculations were undertaken to test the hypothesis concerning the existence of a significant relationship between goal orientation, burnout, and engagement in teachers. Figure 1 shows the result of the analysis undertaken with structural equations and the Maximum Likelihood Method, which confirms the suitability of the model and the constructs considered herein. The model indicates a negative correlation between academic burnout and academic performance $(r=0.59)$, suggesting that high goal orientation scores are paired with high levels of engagement vice versa. Similarly, burnout and goal orientation were found to be negatively correlated $(r=-0.74)$. A similarly strong negative correlation between burnout and engagement $(r=-0.83)$ was also attested. Concerning the fit of the model, the different indices yielded adequate results, confirming the suitability of the factorial structure model proposed to analyze the relationship between goal orientation, burnout and engagement: $x^{2}(17)=48.754, p<0.001 ; x^{2} / \mathrm{gl}=2.867 ; \mathrm{CFI}=0.93 ; \mathrm{NFI}=0.92 ; \mathrm{TLI}=0.90 ; \mathrm{RMSEA}=$ 0.064 , IC $95 \%(0.054-0.097)$. 


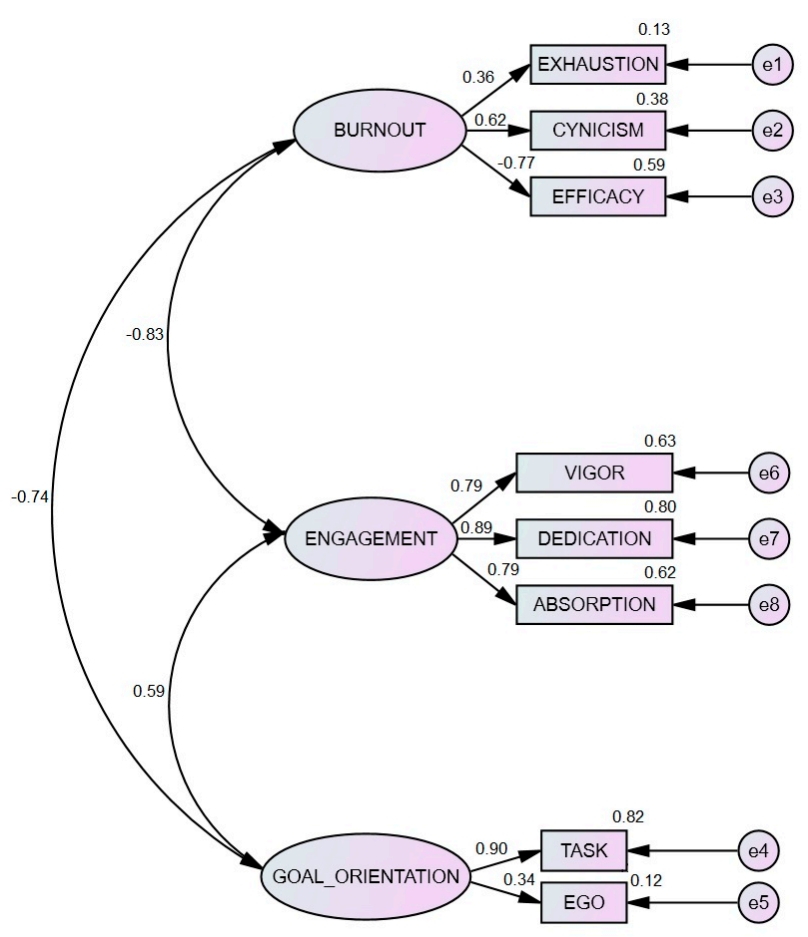

Figure 1. Structural equations model for goal orientation, burnout and academic performance.

\section{Discussion}

The first hypothesis, which related task orientation and engagement and self-efficacy in line with adaptive behaviors was fully confirmed.

There is general consensus that burnout and engagement in teachers are negatively correlated. Armijo and Portalanza [12] link high levels of intrinsic motivation and vigor, dedication and self-efficacy, indicating the commitment of secondary school teachers. Ros [27] found a relationship between the different dimensions of engagement and predominantly intrinsic motivations and self-efficacy in a large sample of primary school teachers. Finally, Stratta et. al. [28] present similar arguments, claiming that high levels of personal motivation and commitment are related to the development of better coping strategies and higher levels of resilience. Therefore, our results are in line with the existing literature $[13,29]$.

The second hypothesis, which related ego orientation and emotional exhaustion and cynicism in line with non-adaptive behaviors was not fully confirmed. Against our prediction, ego orientation is not only correlated with the less adaptive variables of (emotional exhaustion and cynicism), but also with engagement and self-efficacy.

These results indicate that, as pointed out by Fernández [18], extrinsic goal orientation is not necessarily less valuable than goal orientation, in given circumstances, ego orientation can contribute to promoting positive behaviors in achievement environments.

In addition, as pointed out by Matos [30], the teacher's goal orientation affects the way they teach their students and play a prominent role in defining their own goal orientation. Task-oriented teachers tend to emphasize the importance of hard work, effort and motivation, presenting novel and challenging tasks in which mistakes are considered part of the learning process, while ego-oriented teachers tend to emphasize performance results and the student's skill vis-à-vis his or her peers.

Finally, in line with our results, various studies have emphasized a pattern of behavior in which both extrinsic and intrinsic motivations are positively related to adaptive variables such as engagement and even self-efficacy, the most self-determined aspect of burnout [31-33]. 
Few works have explored goal orientation in teachers, despite the important role that this variable plays in teaching approaches and the fact that both goal orientations can lead to positive behaviors in achievement environments.

Our third and fourth hypotheses dealt with engagement and self-efficacy as predictor values over task and ego orientations, and neither was fully confirmed. While self-efficacy and dedication (positive correlation) and cynicism (negative correlation) were found to be valuable predictors of task orientation, only self-efficacy was found to have predictive value over ego orientation. In this regard, our prediction that burnout could be used to predict ego orientations was not confirmed.

In line with our previous results, it is argued that adaptive behaviors (dedication, self-efficacy, and negative cynicism values) can be used to predict goal orientations.

Although few studies have dealt with this issue, some authors have established the predictive value of adaptive behaviors. López and Extremera [8] reveal the relationship between commitment to work (and emotional intelligence) and intrinsic goal orientations in teaching. Burgos et al. [7] reveal that subjective wellbeing is dependent on such variables as dedication and absorption In a similar line but from a different perspective, Rodríguez et al. [6] point out that a combination of high professional demands and low commitment levels leads to low levels of self-efficacy and that, over time, can lead to burnout syndrome and undermine performance.

These results suggest that self-efficacy is related to both types of goal orientation. Vélez et al. [34] claim that burnout factors such as emotional exhaustion and cynicism are negatively correlated with self-efficacy. Similarly, Dios et al. [35] reveal that an unequivocal relationship exists between low self-efficacy and higher burnout, which directly affects teaching performance. As such, low self-efficacy can act as a trigger of burnout syndrome [36].

In this line, Tejedor and Mangas [37] allude to how important it is for teachers to feel self-efficacious with their teaching tasks, in order to keep them committed and reduce the likelihood of burnout. Self-efficacy can also lead to greater resilience, self-esteem, and ability to cope with external stress factors [29]. As pointed out by Lozano and Reyes [13], self-efficacy increases individual control over personal tasks, presenting them as challenging, meaningful, and motivating.

\subsection{Conclusions}

This study contributes to the field in various ways. First, adaptive behaviors in teachers are characterized by goal orientation and greater levels of self-efficacy and engagement. Second, both types of goal orientation can lead to positive behaviors in achievement environments, and this has important practical implications. Third, it is argued that self-efficacy can be used to predict both goal orientations and to be positively related to engagement and negatively so to burnout syndrome. Finally, self-efficacy plays an important role in personality and motivation of people to achieve various goals. Hence, Bandura [38] shows the importance of self-efficacy as a fundamental part of the emotional and physical reactions which people have to face as individual and plural society being a fundamental part of the personality of each person.

\subsection{Limitations of the Study}

The limitations of this study arguably lie in its cross-sectional design since data were collected at a given moment in time. The scores can change from one year to the next and even within the same school year, depending on the teachers' personal and professional circumstances. In addition, the fact that the sample is only made up of volunteers implies that the sample is not necessarily an accurate cross-section of the teaching population in terms of types of school, urban areas, socioeconomic and educational level, and other social variables.

\subsection{Future Prospects}

In the future, it would be fruitful (but challenging) to implement longitudinal models to evaluate the evolution of the constructs under analysis over time. Similarly, it would be interesting to consider 
hitherto neglected socio-demographic variables such as professional status, working hours, working conditions, salary, etc. and analyze their relationship with the variables considered herein. Furthermore, it would be interesting to compare different groups of teachers by age, even by educational levels. Finally, our results encourage us to take into consideration other variables related to engagement and burnout in order to improve teaching practices. In short, finding new questions that help us to define new methodologies that contribute to the professional and personal development of teachers.

Author Contributions: Conceptualization, P.U.S. and C.S.B.; Data curation, P.U.S. and C.S.B.; Investigation, P.U.S. and C.S.B.; Methodology, P.U.S. and C.S.B.; Supervision, P.U.S. and C.S.B.; Writing-original draft, P.U.S. and C.S.B.; Writing-review \& editing, P.U.S. and C.S.B. All authors have read and agreed to the published version of the manuscript.

Funding: This study was performed by Research Group OPIICS (S46_20R), University of Zaragoza (Zaragoza, Spain) and was supported by research funds provided by the Department of Science and Technology of the Government of Aragón (Spain) and the European Social Fund.

Conflicts of Interest: The authors declare no conflict of interest.

\section{References}

1. Mesurado, B.; Laudadío, J. Experiencia profesional, capital psicológico y engagement. Su relación con el burnout en docentes universitarios. Prop. Rep. 2019, 7, 12-40. [CrossRef]

2. Vicente, M.I.; Gabari, M.I. Burnout y factores de resiliencia en docentes de Educación Secundaria. Int. J. Soc. Educ. 2019, 8, 127-152. [CrossRef]

3. Zia, M.; Rezvani, M.; Fattaneh, S. Investigating the effect of emotional intelligence components on organizational maturity and job burn-out. Int. Rev. Man. Bus. Res. 2014, 3, 1767-1772.

4. Escorcia, C.; García, A.; Pérez, B. Síndrome de Burnout y sentimiento de autoeficacia en profesores universitarios. Prop. Rep. 2017, 5, 65-126.

5. Caballero, C.; Palacio, J.; Hederich, C. Síndrome de Burnout: Prevalencia y Factores Asociados en Estudiantes Universitarios del Area de la Salud de la Ciudad de Barranquilla. Ph.D. Thesis, Universidad del Norte, Barranquilla, Columbia, 2012.

6. Rodríguez, A.M.; Martínez, T.S.; Cruz, M.F. Impacto del Burnout en el desarrollo profesional del profesorado universitario. Una revisión de la investigación. Rev. Electon. Interuniv. Form. Profr. 2017, 20, 161-178. [CrossRef]

7. Burgos, A.L.V.; Paris, A.P.D.; Salcedo, A.G.S.; Arriagada, A.A. Psychological well-being and burnout in primary health care professionals in the region of Los Lagos, Chile. Acta Univer. 2018, 28, 56-64. [CrossRef]

8. López, S.M.; Extremera, N. Estado de la cuestión sobre inteligencia emocional y burnout en el profesorado por países, año de publicación, ciclos educativos e instrumentos de evaluación. Prof. Rev. Curr. Form. Prof. 2017, 21, 371-389.

9. Carlotto, M.S.; Câmara, S.G. Psychosocial risks associated with burnout syndrome among university professors. Av. Psicol. Latinoam. 2017, 35, 447-457. [CrossRef]

10. Noreña, H. Estrés Académico y Estrategias de Afrontamiento en Estudiantes de Primer, Segundo y Tercer Semestre de la Facultad de Ingeniería de la Universidad de Antioquia. Ph.D. Thesis, Universidad de Antioquia, Antioquia, Equador, 2018.

11. Seligman, M.; Steen, T.; Park, N.; Peterson, C. Positive psychology progress. Empirical validation of interventions. Am. Psychol. 2005, 60, 410-421. [CrossRef]

12. Armijo, M.I.; Portalanza, C.A. Diagnóstico de la calidad de vida laboral, engagement y burnout en trabajadores de una institución de educación superior del Ecuador. INNOVA Res. J. 2017, 2, 153-165. [CrossRef]

13. Lozano, C.R.; Reyes, M. Docentes universitarios: Una mirada desde la Autoeficacia general y engagement laboral. Rev. Digit. Investig. Docencia Univ. 2017, 134-148. [CrossRef]

14. González, T.M.P.; Torres, L.H.; Carreres, A.L. Fortalezas y virtudes personales del profesorado y su relación con la eficacia docente. Int. J. Dev. Educ. Psychol. 2017, 7, 141-150. [CrossRef]

15. Vallejo, M. Una aproximación al síndrome de burnout y las características laborales de emigrantes españoles en países europeos. Rev. Psicol. Trab. Organ. 2017, 33, 137-145. [CrossRef]

16. Nicholls, J.G. Achievement motivation: Conceptions of ability, subjective experience, task choice and performance. Psycol. Rev. 1989, 21, 328-346. [CrossRef] 
17. Ames, C. Achievement goals, motivational climate and motivational processes. In Motivation in Sport and Exercise; Roberts, G.C., Ed.; Human Kinetics: Champaign, IL, USA, 2002; pp. 161-176.

18. Fernández, J.M. Desempeño docente y su relación con orientación a la meta, estrategias de aprendizaje y autoeficacia. Un estudio con maestros de primaria de Lima, Perú. Univ. Psychol. 2008, 7, 385-401.

19. Franco, V.; González, R.; Souto, A. La percepción de estresores académicos según las orientaciones motivacionales a metas en estudiantes universitarios. Eur. J. Investig. Health Psychol. Educ. 2019, 9, 189-200. [CrossRef]

20. Usán, P.; Salavera, C.; Mejías, J. Relaciones entre la inteligencia emocional, el burnout académico y el rendimiento en adolescentes escolares. Rev. CES Psicol. 2020, 13, 125-139. [CrossRef]

21. Schaufeli, W.B.; Leiter, M.P.; Maslach, C.; Jackson, S.E. The Maslach Burnout Inventory: General Survey (MBI-GS); Palo Alto Consulting: Palo Alto, CA, USA, 1996.

22. Bresó, E.; Salanova, M.; Schaufeli, W.B.; Nogareda, C. Sindrome de Estar Quemado por el Trabajo Burnout (III): Instrumento de Medición; Instituto Nacional de Seguridad de Higiene en el Trabajo, Ministerio de Trabajo y Asuntos Sociales: Madrid, Spain, 2007.

23. Schaufeli, W.; Martínez, I.; Marques-Pinto, A.; Salanova, M.; Bakker, A. Burnout and engagement in university students: A crossnational study. J. Cross Cult. Psycol. 2002, 33, 464-468. [CrossRef]

24. Roberts, G.; Treasure, D.; Balagué, G. Achievement goals in sport: The development and validation of the perception of success questionnaire. J. Sport Sci. 1998, 16, 337-347. [CrossRef]

25. Martínez, C.; Alonso, N.; Moreno, J.A. Análisis factorial confirmatorio del “Cuestionario de Percepción de Éxito (POSQ)" en alumnos adolescentes de Educación Física. In IV Congreso de la Asociación Española de Ciencias del Deporte; González, M.A., Sánchez, J.A., Areces, A., Eds.; Xunta de Galicia: Coruña, Spain, 2006; pp. 757-761.

26. Asociación Médica Mundial (AMM). Declaración de Helsinki. Principios Éticos para las Investigaciones con los Seres Humanos; Asociación Médica Mundial: Geneva, Switzerland, 2002.

27. Ros, R. Engagement, autoeficacia, optimismo y situación laboral en docentes de educación básica. Rev. Electrob. Investig. Docencia 2016, 15, 101-116.

28. Stratta, P.; Capanna, C.; Patriarca, S.; de Cataldo, S.; Bonanni, R.L.; Riccardi, I.; Rossi, A. Resilience in adolescence: Gender differences two years after the earthquake of L'Aquila. Personal. Individ. Differ. 2013, 54, 327-331. [CrossRef]

29. Cruz, D.M.; Puentes, A. Relationship between different dimensions of the Burnout syndrome and the coping strategies implemented by security guards at a private corporation from Tunja. Psicogente 2017, 20, 268-281.

30. Matos, L. School Culture, Teachers' and Students' Achievement Goals as Communicating Vessels. A Study in Peruvian Secondary Schools. Ph.D. Thesis, Katholieke Universiteit, Leuven, Belgium, 2005.

31. Pena, M.; Rey, L.; Extremera, N. Life satisfaction and engagement in elementary and primary educators: Differences in emotional intelligence and gender. Rev. Psicodidact. 2012, 17, 341-358. [CrossRef]

32. Salanova, M.; Martínez, I.M.; Llorens, S. Una mirada más "positiva" a la salud ocupacional desde la Psicología Organizacional Positiva en tiempos de crisis: Aportaciones desde el equipo de investigación WoNT. Papel Psicol. 2014, 35, 22-30.

33. Schauffeli, W.; Salanova, M. Efficacy or inefficacy, that's the question: Burnout and work engagement, and their relantionships with efficacy believes. Anxiety Stress Coping 2007, 20, 177-196. [CrossRef]

34. Vélez, A.P.; López, J.J.; González, J.B. Habilidades emocionales y profesionalización docente para la educación inclusiva en la sociedad en red. Contextos Educ. Rev. Educ. 2017, 20, 201-215. [CrossRef]

35. Dios, I.; Calmaestra, J.; Rodríguez, A.J. Validación de la escala de competencias docentes organizacionales y didácticas para educadores. Rev. Mex. Investig. Educ. 2018, 23, 281-302.

36. Peña, J.E.; Raso, P.C.; Ferrero, B.S. El Sindrome de Burnout en los Docentes; Pirámide: Madrid, Spain, 2018.

37. Tejedor, E.M.; Mangas, S.L. La autoeficacia y la autorregulación como variables moderadoras del estrés laboral en docentes de Educación Primaria. Univ. Psychol. 2016, 15, 15-28.

38. Bandura, A. Self-efficacy beliefs of adolescents. In Adolescence and Education; Pajares, F., Urdan, Y.T., Eds.; Information Age Publishing: Greenwich, UK, 2006; pp. 307-335.

(C) 2020 by the authors. Licensee MDPI, Basel, Switzerland. This article is an open access article distributed under the terms and conditions of the Creative Commons Attribution (CC BY) license (http://creativecommons.org/licenses/by/4.0/). 